\title{
Sobre as competências crítica e comportamental na Educação Estatística
}

\author{
About critical and behavioral competences in Statistics Education
}

Celso Ribeiro Campos ${ }^{1}$

Andréa Pavan Perin ${ }^{2}$

\section{Resumo}

As pesquisas em Educação Estatística têm avançado intensamente com o planejamento de atividades que visam ao desenvolvimento de três competências, a literacia, o raciocínio e o pensamento estatístico, as quais permitem uma aprendizagem mais significativa dos conceitos dessa ciência. $\mathrm{O}$ aprofundamento dessas pesquisas permitiu a identificação de outra competência também importante para esse universo, que é a competência crítica. $\mathrm{O}$ objetivo deste trabalho é aprofundar a reflexão sobre a competência crítica, evidenciando a sua evolução em pesquisas desenvolvidas no âmbito da Educação Estatística, e apresentar uma quarta competência, a qual chamamos de competência comportamental. Em nossas análises, pudemos observar que a competência crítica se desenvolve com base em duas vertentes, a sociopolítica e a epistemológica. Por fim, tomando como base diversos exemplos práticos observados dentro e fora da sala de aula, mostramos como a competência comportamental foi identificada.

Palavras-chave: Educação estatística; Competência crítica; Competência comportamental.

\begin{abstract}
Research in Statistics Education has advanced intensely with the planning of activities aimed at the development of three competences, literacy, reasoning, and statistical thinking, which allow more meaningful learning of the concepts of this science. The deepening of these researches allowed the identification of another competence also important for this universe, which is the critical competence. The aim of this paper is to deepen the reflection on critical competence, highlight its evolution in research developed in the field of Statistical Education, and to present a fourth competence, which we call behavioral competence. In our analysis, we have observed that critical competence develops itself on two streams, sociopolitical and epistemological. Finally, based on several practical examples observed inside and outside the classroom, we show how behavioral competence has been identified.
\end{abstract}

Keywords: Statistics education; critical competence, behavioral competence.

\section{Introdução}

A Estatística, por ser uma ciência de análise de dados, está presente em diversos contextos. Por essa razão, compreendê-la é fundamental para que as pessoas possam entender, avaliar e se posicionar frente aos dados estatísticos que circulam nos mais diversos meios de comunicação.

\footnotetext{
Submetido em: 25/09/2019 - Aceito em: 17/01/2020 - Publicado em: 07/02/2020

${ }^{1}$ Doutor em Educação Matemática pela UNESP. Professor da PUC-SP, Brasil. crcampos@ @ucsp.br

2 Doutora em Educação Matemática pela UNESP. Professora da FATEC-Itapetininga/SP, Brasil. andreapavanperin@gmail.com

Zetetiké, Campinas, SP, v.28, 2020, p.1-19-e020003 
DOI: $10.20396 /$ zet.v28i0.8656795

Reconhecida a frequência da Estatística no cotidiano das pessoas, pesquisadores da Educação Estatística começaram a discutir a importância dessa ciência ser ensinada desde a Educação Básica até o Ensino Superior. Tal discussão foi pontuada, inicialmente, por meio de dois documentos, sendo um da American Statistical Association (ASA) e um do National Council of Teachers of Mathematics (NCTM), publicados nos anos de 1960 e 1967, respectivamente. Dada a expressividade adquirida por esses documentos, a partir de 1989, revistas importantes da área publicaram artigos que destacavam duas ações que mereceriam atenção nos anos seguintes: inserir a Estatística em todos os níveis escolares e dar maior atenção às formas de conduzir os processos de ensino-aprendizagem dessa ciência (Zieffler, Garfield \& Fry; 2018).

No contexto brasileiro, a preocupação com os processos de ensino-aprendizagem de Estatística também tem ganhado espaço nos documentos oficiais. No final da década de 1990, com a publicação dos Parâmetros Curriculares Nacionais, a Estatística e a Probabilidade foram incorporadas oficialmente à estrutura curricular da Educação Básica (Samá, 2018). Mais recentemente, a promulgação da Base Nacional Comum Curricular (MEC, 2017) ratifica a inserção da Estatística e da Probabilidade na Educação Básica e sugere a abordagem de conceitos estatísticos por meio de situações da vida cotidiana, das ciências e da tecnologia (Cazorla, Silva \& Santana; 2018).

Tanto no contexto nacional quanto no internacional, a divulgação desses documentos da ASA e do NCTM levou muitos pesquisadores a desenvolverem estudos voltados à Educação Estatística. Desde então, as pesquisas nessa área têm avançado em todo o mundo, e uma das grandes conquistas foi a identificação das competências estatísticas que devem ser desenvolvidas nos estudantes para uma aprendizagem efetiva dos conceitos dessa ciência.

Nessa linha, foram identificadas as competências relacionadas ao pensamento estatístico, ao raciocínio estatístico e à literacia (ou letramento) estatística. Desde o princípio, observou-se que existiam alguns aspectos comuns nessas três competências que deveriam ser identificados. Uma primeira suposição foi a de que essas competências formariam um entrelaçamento, o que foi representado por Delmas (2002), como mostra a figura 1.

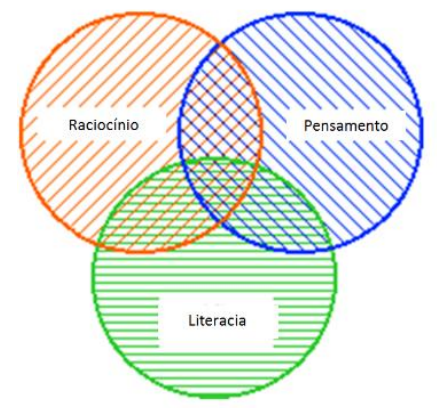

Figura 1- Domínios independentes com alguma intersecção Fonte: Delmas, 2002, p. 4 - tradução nossa. 
DOI: $10.20396 /$ zet.v28i0.8656795

Outra possibilidade observada pelo mesmo autor sugere que a literacia teria um domínio mais abrangente, com as demais competências inseridas nela, conforme sugere a figura 2.

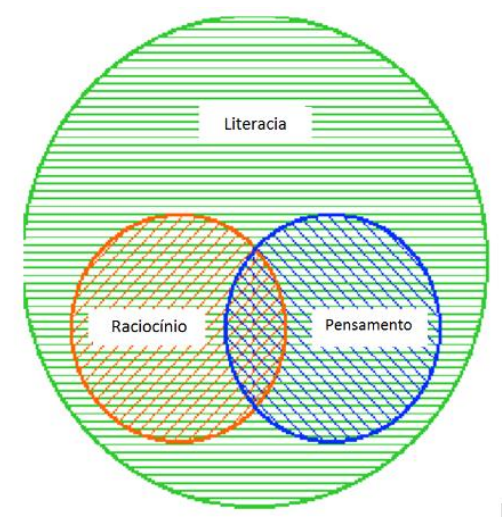

Figura 2- Raciocínio e pensamento contidos na literacia

Fonte: Delmas, 2002, p. 4 - tradução nossa.

Essa segunda interpretação foi mais aceita pela comunidade acadêmica e passou-se a trabalhar com mais afinco no âmbito da literacia, buscando-se identificar seus determinantes, níveis de aprofundamento, como avaliar seu desenvolvimento, suas conexões com a Modelagem Matemática, com outros letramentos (Campos \& Coutinho, 2019; Coutinho \& Campos, 2018) e com as outras competências.

O aprofundamento das pesquisas sobre a literacia possibilitou a identificação da competência crítica, a qual tem servido de base para o que atualmente denominamos de Educação Estatística Crítica (Campos, 2007; Campos, Jacobini \& Wodewotzki 2011a; Campos, Jacobini \& Wodewotzki, 2011b; Campos, 2016; Perin, 2016). Outros autores como Sampaio (2010), Hollas \& Bernardi (2018), Melo \& Maçal (2012) também apresentam valiosas contribuições para o desenvolvimento de estudos nesse âmbito.

As pesquisas em Educação Estatística são bastante dinâmicas e pesquisadores de várias partes do mundo contribuem para o seu constante aprofundamento, fazendo com que essa área tenha uma evolução constante nos seus mais diversos aspectos. Buscando contribuir para essa evolução, temos identificado uma característica peculiar, que são fatores emocionais, sociais, psicológicos e/ou cognitivos que afetam a tomada de decisão dos estudantes que aprendem Estatística. Tais fatores se manifestam de diversas formas em seus comportamentos e têm influenciando de maneira não positiva o aprendizado dessa disciplina.

Nesse contexto, o objetivo deste trabalho é aprofundar a reflexão sobre a competência crítica, evidenciando a evolução dessa competência nas pesquisas em Educação Estatística. Além disso, temos o objetivo de apresentar uma nova competência que nos parece importante para esse universo, que é a competência que chamamos de comportamental, a qual pode influenciar significativamente o relacionamento do estudante com os conceitos de Estatística, com consequências sobre diversos aspectos relacionados à interpretação de dados. 
DOI: $10.20396 /$ zet.v28i0.8656795

Nossa intenção é mostrar que as três competências inicialmente identificadas (literacia, pensamento e raciocínio), precisam ser complementadas com as outras duas (crítica e comportamental) para proporcionar um melhor entendimento da dinâmica de ensinoaprendizagem da Estatística nos diversos níveis de escolaridade.

\section{O aprofundamento teórico da competência crítica}

A identificação das três competências estatísticas originais foi um marco na evolução da Educação Estatística, pois permitiu a construção dos seus fundamentos teóricometodológicos de maneira mais objetiva. Também direcionou as pesquisas para a determinação das características, formas de desenvolvimento, avaliação e níveis de aprofundamento dessas competências.

Campos (2007) em seu estudo verificou que o desenvolvimento dessas competências requer um ambiente no qual os alunos se insiram em uma prática investigativa; trabalhem com temas dos seus interesses; estejam em contato com dados que tenham relevância para um determinado contexto; manipulem uma diversidade de variáveis e vivenciem o processo de geração e análise dos dados; desenvolvam atividades em grupos; usem a tecnologia; sejam avaliados pelas relações e julgamentos que estabelecem para um conjunto de dados. Para tanto, o autor advoga que as atividades didáticas devem tratar sempre de assuntos relevantes para os alunos, ligados ao seu cotidiano e/ou à sua formação profissional. Campos (op. cit.) ao estudar estratégias pedagógicas com vistas ao desenvolvimento dessas competências percebeu que os preceitos da Modelagem Matemática na perspectiva da Educação Matemática se mostravam adequados para o trabalho em sala de aula.

Uma condição básica para a elaboração de trabalhos de Modelagem Matemática, nessa perspectiva, é a contextualização dos dados, os quais devem provir de pesquisas reais, preferencialmente coletados pelos próprios alunos. Nesse sentido, a Modelagem Matemática tem como objetivo proporcionar aos estudantes, além da habilidade de lidar com noções matemáticas, a de aplicar essas noções em diferentes contextos. Assim, intenciona desenvolver a capacidade de refletir sobre essas aplicações, de forma que o estudante possa exercer uma cidadania crítica (Campos, Wodewotzki \& Jacobini, 2011a). A base para desenvolver trabalhos com essas características é o diálogo, o qual favorece a aprendizagem significativa, política e democrática. Espera-se com isso que o estudante seja capaz de reconhecer, refletir e ponderar sobre a aplicação sociopolítica do conhecimento.

Tendo em vista essa compreensão da Modelagem Matemática, Campos (2007), salientou que ao trazer para a sala de aula dados reais e contextualizados, estaria o professor tematizando e problematizando o ensino, assim como, estimulando o debate e o diálogo. Com isso, o autor afirma que estimula a desierarquização do ambiente da sala de aula entre os alunos e com o professor e pratica a democracia no contexto pedagógico. Assim, Campos (op. cit.) observou que os princípios da Educação Crítica e da Educação Matemática Crítica, conforme estudo de Freire (1965, 1979 e 2014) e Skovsmose (2008, 2014a e 2014b), respectivamente, complementam as estratégias pedagógicas favoráveis ao desenvolvimento 
DOI: $10.20396 /$ zet.v28i0.8656795

das competências estatísticas. Mais especificamente, ele concebeu a Educação Estatística com um enfoque diferenciado e integrador dessas ideias e tornou concreta a convergência entre os fundamentos da Educação Estatística e da Educação Crítica.

Com base nessa compreensão, Campos (2016) salientou que as competências estatísticas conduzem então ao desenvolvimento de uma quarta competência, a crítica. Isso porque, ao trazer para a sala de aula situações problemas vivenciadas pelos estudantes, eles seriam desafiados a pensar o que os dados indicam sobre a sua realidade e por isso os tornariam mais críticos na medida em que os temas tratados versem sobre questões sociais, econômicas, políticas, ambientais, etc. Para o autor, problemas baseados em dados reais são a chave para desenvolver a criatividade, a criticidade e fomentar a reflexão sobre a sua própria realidade.

Nessa linha, entendemos que ao resolver problemas provenientes da modelagem e investigar situações que remetem a dados de ordem social, política, econômica, etc., as tarefas não conduzem os estudantes apenas à sua solução, mas, sobretudo, ao diálogo e ao debate em torno da realidade exposta, estimulando reflexões e ações sobre a forma com que se vive e se conduz o mundo que nos cerca.

Dessa forma, o ambiente necessário ao desenvolvimento das competências estatísticas, as quais preocupam-se com um olhar multifocal, atento a tudo o que envolve um processo de investigação estatística, é indissociável dos elementos (diálogo, problematização, reflexão e conscientização) citados por Freire (2014) como fundamentais à Educação Crítica. Adicionalmente, esses elementos permitirão que a educação cumpra também a sua dimensão política, e é por essa razão que Campos (2016) afirma que a competência crítica está imbricada às competências estatísticas.

Ao falar dessa quarta competência, Campos (op. cit.) argumenta que não se trata de criar uma nova dimensão para a Educação Crítica, mas de se destacar seus aspectos dentro da Educação Estatística de forma que as atividades pedagógicas possam ser melhor planejadas e avaliadas nesse contexto.

Por sua vez, Perin (2019), ao buscar as contribuições do ambiente de Modelagem Matemática na perspectiva do desenvolvimento das competências da Educação Estatística Crítica, observou, com base nas falas dos estudantes, que a competência crítica pode ser construída com base em duas vertentes distintas: a sociopolítica e a epistemológica.

a) A crítica sociopolítica é aquela que aborda questões ligadas ao entendimento de aspectos do mundo em que vivem os indivíduos, bem como de suas atuações nesse mundo. Em sua pesquisa, Perin (op. cit.) identificou que após a realização de um trabalho de modelagem, os alunos além de questionarem suas relações na sociedade também buscaram identificar maneiras diferentes de atuar de forma a serem mais participativos e questionadores no que diz respeito a um conjunto de ações de interesse social e/ou comunitário, no qual a atividade desempenhada é revertida para além de si mesmo, ou seja, em favor do outro. A seguir, reproduzimos o diálogo dos estudantes que permitiu essa compreensão. 
A3G1: [...] Sem contar a dificuldade que foi conseguir os dados [...] precisamos insistir muito!

A1G1: Foi triste perceber que as pessoas faziam na brincadeira!

A3G1: Mas o legal é que mudei minha visão de responder pesquisas depois desse trabalho, antes eu não dava bola, também não respondia direito.

A1G3: [...] desenvolver essa pesquisa mexeu com a gente [...]. Pensamos naquele dia em que o pessoal do hospital estava aqui para doação de medula, eles tiveram que quase implorar aqui na sala para a gente descer lá [...] e que agora que estivemos do outro lado, nós ficamos bem mais sensíveis e abertos para essas coisas (Perin, 2019, pp. 188-189).

Essas falas revelam a preocupação dos alunos com sua formação ético-moral, de maneira a consolidar melhor os valores sociais compatíveis com o exercício da cidadania. Ao relatarem as dificuldades encontradas no momento da coleta de dados, os estudantes promoveram reflexões que ampliaram suas habilidades sociais, tomando consciência de aspectos importantes do mundo em que vivem e apontaram caminhos que levam à transformação.

b) A crítica epistemológica refere-se às percepções dos alunos em relação ao conhecimento estatístico e está fortemente relacionada com elementos que caracterizam o desenvolvimento das competências estatísticas. Com base no trecho a seguir, extraído de Perin (2019, p. 195), fazemos a discussão desses elementos.

A2G3: [...] Vi que a Estatística não é simplesmente ver os números ou porcentagem, e sim que é um trabalho difícil com muitos obstáculos e surpresas no caminho [...]

A2G5: Hoje em dia olho tudo com mais cautela, verificando as fontes das informações e analisando todo o cenário para tirar minha conclusão sobre aqueles dados [...].

A2G1: [...] antes de fazer todo esse trabalho e as discussões que tivemos em sala eu via o mundo como ele aparenta ser, mas agora sinto que tenho a capacidade de olhar as coisas mais a fundo, analisar melhor a situação e tomar melhor a minha decisão. Já penso: Quem fez? Como fez? Respeitou todos os cuidados?

A2G2: [...] antes para mim um número dado era exatamente aquele, hoje eu penso que existe um intervalo de valores possíveis [...].

Ao reconhecerem a relevância de articular conhecimentos conceituais com o processo de amostragem para verificar se determinadas conclusões podem ser tiradas com base em informações disponíveis, vê-se características da literacia estatística. Já o pensamento estatístico pode ser percebido quando os alunos reconhecem que a análise de dados indica uma tendência e não uma certeza em relação aos fenômenos. Nessas falas, percebemos que os alunos foram capazes de compreender que um estudo estatístico não pode dar conta da totalidade de variáveis que envolvem um fenômeno, o que possui características do raciocínio estatístico.

Diante isso, percebemos que alunos reconhecem que estar bem informado significa analisar o que os outros dizem, avaliar e questionar o que é mostrado em pesquisas, gráficos e números, ou seja, eles compreendem a necessidade de olhar de forma crítica para o conhecimento. Campos (2016) afirma que a competência crítica atinge seu ápice quando os 
estudantes clamam por seus direitos, demandam por justiça social, levantado a voz contra sistemas de opressão impostos a eles.

Isso posto, entendemos que embora as três competências originais versem de certa forma sobre a necessidade de haver criticidade para o seu desenvolvimento, a competência crítica deve se sobressair e não ficar submetida a elas. Assim como Campos, Jacobini \& Wodewotzki (2011) e Perin (2019), que identificaram e aprofundaram o conhecimento sobre a literacia, o raciocínio e o pensamento estatísticos, propuseram ações pedagógicas com vistas ao seu desenvolvimento, a competência crítica deve ter o mesmo tratamento e, conforme mostramos, ela encontra um terreno fértil na estratégia pedagógica da Modelagem Matemática.

\section{A competência comportamental}

Alguns conceitos de Estatística são bastante comuns de serem aplicados na vida cotidiana das pessoas, pois estão presentes na mídia com muita frequência. Contudo, percebese que as pessoas comuns por vezes se apropriam do conceito estatístico de uma forma peculiar, sem uma preocupação de rigor quanto ao seu uso correto ou não. Nossa intenção aqui não é fazer juízo de valor, mas tentar entender o comportamento das pessoas que usam o conceito de forma imprópria e refletir sobre a presença de uma competência comportamental da Educação Estatística. Para chegar a isso, citaremos alguns exemplos.

Exemplo 1: Habitantes de cidades grandes, tais como São Paulo, estão habituados a ouvir no rádio pela manhã informações do trânsito, como por exemplo: "O trânsito agora apresenta X quilômetros de congestionamento, valor que está dentro da média para o dia e horário". No dia 06 de setembro de 2019 houve uma greve de motoristas de ônibus em São Paulo e o trânsito ficou bastante caótico. Durante o longo congestionamento que se formou nas principais vias da cidade, foi possível ouvir em uma estação de rádio uma entrevista do prefeito da cidade dizendo: "Estamos operando abaixo da média [...]”3. Esses exemplos nos fazem refletir se o que essas pessoas entendem como média é o mesmo conceito formal que conhecemos na Estatística ou não. Em particular, nos toca refletir sobre o que é estar dentro da média. Vamos apresentar outro exemplo antes de prosseguir com a análise deste.

Exemplo 2: Perin (2019), apresentou um estudo de modelagem realizado com alunos de um curso superior na disciplina de Estatística, no qual um grupo pesquisou algumas variáveis a respeito do número de alunos da faculdade e apresentou uma representação em boxplot da variável idade, que está na figura 3.

${ }^{3}$ http://cbn.globoradio.globo.com/media/audio/273670/sistema-nao-e-mais-ou-menos-eficiente-pela-quantid.htm 
DOI: 10.20396/zet.v28i0.8656795

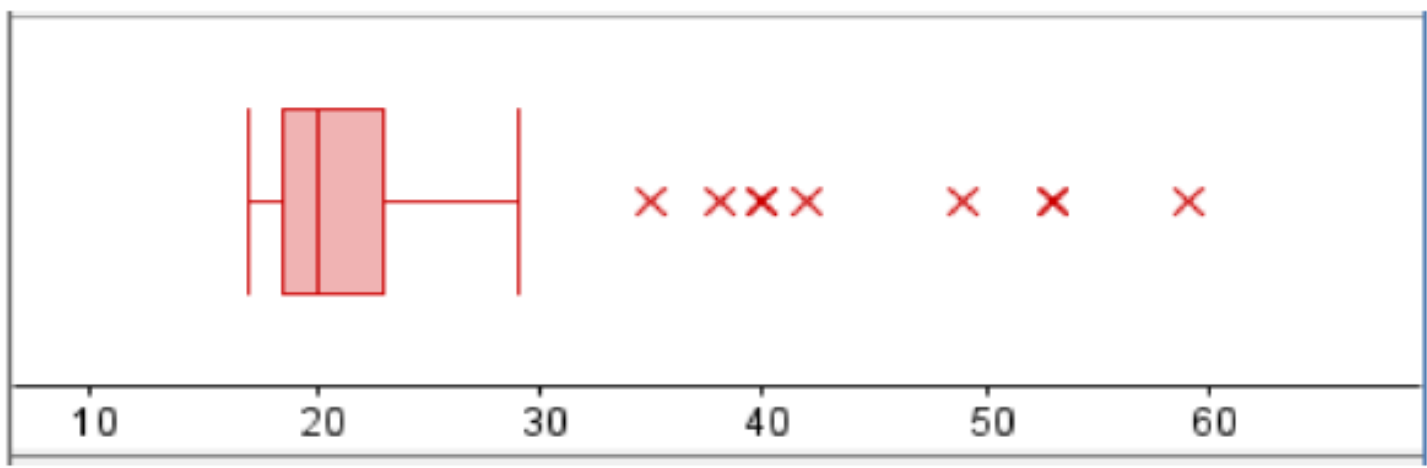

Figura 3 - Representação da variável idade dos entrevistados.

Fonte: Perin (2019, p. 136)

O boxplot, diagrama de caixa ou caixa de bigode é um gráfico bastante útil para a análise de concentração e dispersão dos dados. A caixa do desenho é limitada à esquerda pelo primeiro quartil $(\mathrm{Q} 1)$ e à direita pelo terceiro quartil $(\mathrm{Q} 3)$ e tem dentro de si uma linha que representa o posicionamento da mediana. A extensão da caixa (que na figura 3 se vê na horizontal) representa a amplitude interquartílica, que contém $50 \%$ dos dados de uma distribuição. Já as linhas que saem da caixa à direita e à esquerda (os bigodes), foram construídos considerando-se 1,5 vezes a amplitude interquartílica para abarcar cerca de $99 \%$ dos dados, considerando que a linha a direita deve se estender até a maior observação abaixo do limite para outliers superiores, enquanto que a linha a esquerda deve se estender até a menor observação acima do limite para outlier inferiores (Bussab \& Morettin, 2005). Os valores extremos foram representados por um " $\times$ " posicionado em região externa ao bigode.

A representação que vemos na figura 3 foi feita pelos alunos, e nela é possível observar diversos valores discrepantes posicionados à direita do limite do bigode. Na sequência, reproduzimos a fala dos alunos do grupo que fez esse trabalho, conforme descrito em Perin (2019).

A1G1: Aqui está nossa primeira variável, a idade. É possível perceber pelo boxplot que tem muitos dados discrepantes. Você pode ver que o aluno mais novo tem 17 anos e o mais velho tem 59, mas ele está mais concentrado... fica mais concentrado entre 17 e 23 anos, a maioria dos alunos está dentro dessa faixa que varia pouco. Outras idades você já percebe que fica mais afastado, mais largo. Nós vamos falar melhor sobre isso quando assim que apresentarmos a média da idade.

A2G1: Nós chegamos a fazer o...

A4G1: Histograma.

A2G1: Isso!!! E vimos que a maioria das pessoas está dentro dessa faixa aqui ${ }^{4}$. E se excluíssemos alguns desses alunos ${ }^{5}$ a média também ficou bem representada nesse lugar (Perin, op.cit, p. 136).

Pela fala dos alunos, é possível perceber que eles tinham calculado a média aritmética das idades considerando todos os resultados, mas, excluindo os valores discrepantes, eles chegaram a um outro resultado que os deixou mais confortáveis ("a média ficou bem representada"). Perin (op. cit., p. 137)) comenta:

\footnotetext{
${ }^{4} \mathrm{O}$ aluno aponta a faixa entre 18 e 24 anos

${ }^{5} \mathrm{O}$ aluno aponta para valores discrepantes
} 
Também julgamos interessante fazer uma reflexão sobre a fala do aluno 2 a respeito de excluir os valores extremos para o cálculo da média. Em uma coleta de dados podemos nos deparar com valores que fogem da normalidade e que provavelmente causarão irregularidades nos resultados obtidos por meio de algoritmos e sistemas de análise. No entanto, em um processo de análise de dados consideramos importante olhar para esses valores por dois aspectos: esses valores podem viesar negativamente todo o resultado de uma análise; o comportamento dos outliers pode ser justamente o que está sendo procurado e compreendê-los pode ser fundamental para produzir medidas relevantes ao estudo que está sendo desenvolvido. Contudo, entendemos que o aluno teve uma postura curiosa ao retirar esses valores e calcular novamente a média. Porém, esses valores podem receber não apenas esse tratamento, mas sim outros olhares que permitam perceber os motivos da sua existência.

Exemplo 3: A mesma autora relata ainda a apresentação do trabalho de outro grupo que também pesquisou a idade dos alunos da faculdade, assim como a renda mensal (em reais), e que mostrou os gráficos que estão na figura 4 .
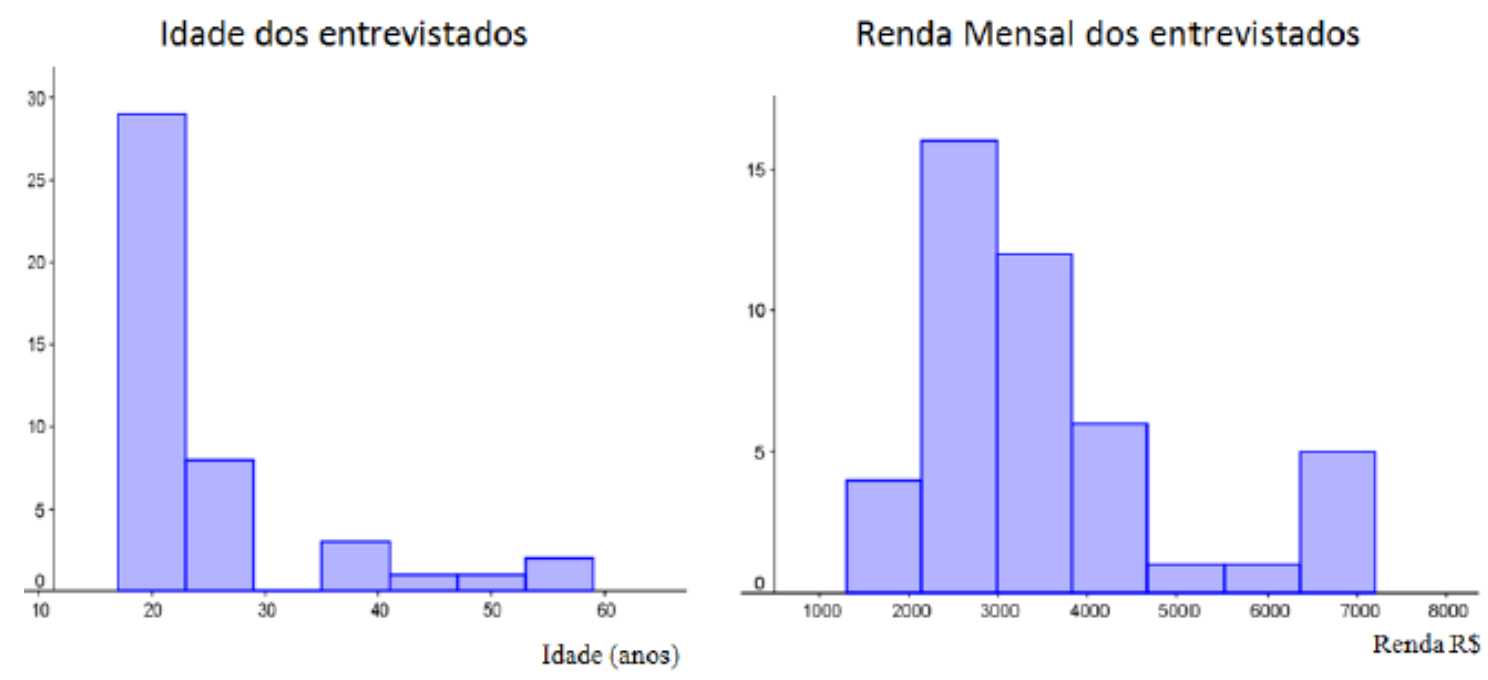

Figura 4 - Diagrama elaborado pelos alunos.

Fonte: Perin (2019, p. 142)

As falas dos alunos sobre o comportamento das variáveis diferem substancialmente da que foi observada anteriormente.

A2G5: Analisando o gráfico da distribuição da idade e como nas apresentações dos outros grupos percebemos que a idade não varia muito né! Quer dizer varia, mas o que quero afirmar é que a maioria está aqui, nessa região ${ }^{6}$, é um grupo de alunos jovens. [...] Mas também fico feliz em ver que pessoas que não tiveram oportunidade quando eram mais novas estão estudando agora. [...] Já o gráfico da renda apresenta uma forma bastante diferente - excluindo essa última coluna, nós poderíamos dizer que a renda baixa é para uma quantidade pequena de pessoas, depois aumentando a renda, aumenta-se o número de pessoas e por último, aumentando a renda, cai o número de pessoas.

A1G5: Vou falar um pouquinho sobre o que nós pensamos quando construímos esse gráfico da renda: na nossa realidade foi assim, como vocês estão vendo. Mas na

\footnotetext{
${ }^{6} \mathrm{O}$ aluno mostra as duas primeiras colunas
} 
DOI: 10.20396/zet.v28i0.8656795

prática, pensando numa população maior eu acho que ele ficaria parecido com o gráfico da idade (Perin, 2019, pp. 142-143).

A autora ressalta essa diferença:

Diferentemente dos alunos do Grupo $2^{7}$, os do Grupo 5 se posicionaram com um outro olhar para os valores mais afastados de onde se concentram maior parte dos elementos. Isso pode ser percebido a partir dos comentários que fizeram acerca da idade dos alunos que estão cursando o nível superior. Eles não se posicionaram de maneira a ignorar esses valores, já que eram poucos em comparação com a frequência das outras idades, mas buscaram compreendê-los, apontando aspectos positivos desse fato (Perin, 2019, p. 143).

Essa ideia de excluir valores discrepantes para o cálculo da média precisa ser analisada com cuidado. Os outliers podem indicar erro de medida ou erro de resposta, casos em que eles devem ser excluídos para não viesar a média (por exemplo). Contudo, esses valores discrepantes podem ser valores reais, ou seja, uma parte do todo, que se excluídos podem provocar uma alteração inadequada dos dados, conduzindo a uma falha na interpretação do cenário em estudo.

Exemplo 4: Em uma oficina pedagógica que fizemos com professores de Matemática e alunos dos cursos de Mestrado e Doutorado em Educação Matemática, apresentamos um boxplot relativo número de habitantes dos estados brasileiros. Sem revelar a escala de valores, apresentamos aos participantes o gráfico mostrado na figura 5 e perguntamos se deveríamos ou não considerar os valores discrepantes no cálculo da média do número de habitantes dos estados.

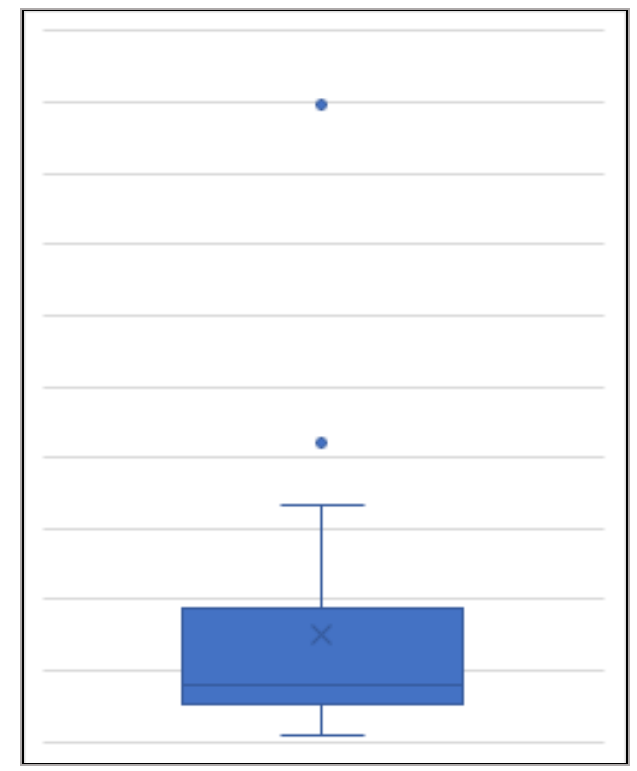

Figura 5 - Boxplot $t^{8}$ mostrando o número de habitantes dos estados brasileiros.

Fonte: elaboração própria com dados de IBGE (2016).

\footnotetext{
7 Apesar de citar os alunos do grupo 2, a autora aqui está se referindo ao grupo 1, o qual apresentamos na figura 1.

${ }^{8}$ Esse gráfico foi feito por meio do Excel, o qual posiciona o boxplot na vertical.
} 
DOI: 10.20396/zet.v28i0.8656795

Alguns professores responderam que sim, que deveríamos excluir os valores extremos. Perguntados sobre o (s) motivo (s) da exclusão, responderam que eram outliers, por isso viesariam o cálculo da média.

Na sequência da atividade, mostramos os valores da escala e identificamos os estados com resultados discrepantes (figura 6). Aproveitamos para debater sobre a resposta dos professores que haviam excluído São Paulo e Rio de Janeiro do cálculo da média do número de habitantes dos estados brasileiros.

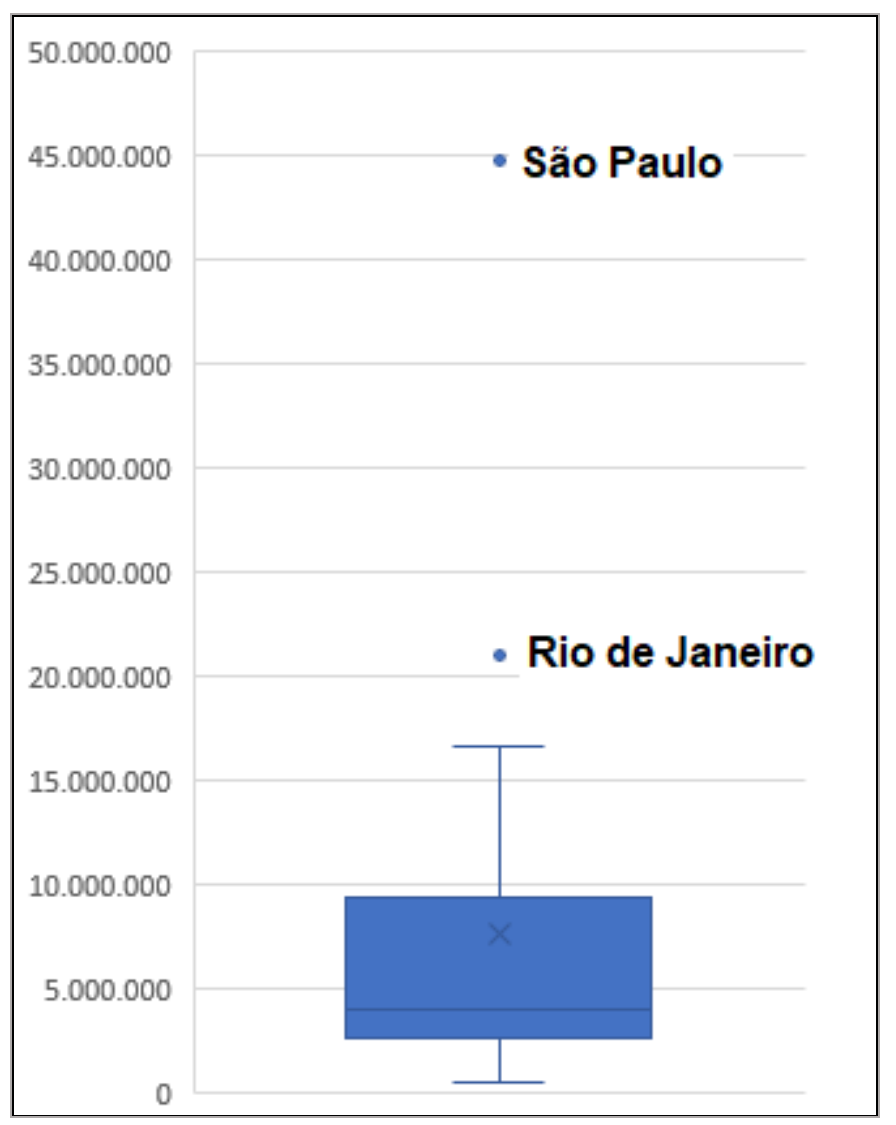

Figura 6 - Boxplot do número de habitantes dos estados com identificação da escala e das observações discrepantes.

Fonte: elaboração própria com dados de IBGE (2016).

Pode parecer que os professores que achavam que os valores discrepantes deveriam ser excluídos agiram de forma semelhante aos alunos que excluíram as observações de idade mais elevadas. Contudo, existe uma diferença significativa de interpretação, pois os professores não dispunham de todas as informações sobre o problema. Antes de tomar partido sobre a exclusão ou não dos valores extremos, eles deveriam indagar sobre a origem dos dados e refletir sobre a veracidade das informações. Aparentemente, os professores optaram por uma reação mais intuitiva e menos reflexiva.

Vamos agora voltar ao primeiro exemplo que apresentamos, que se refere ao trânsito da cidade de São Paulo. A Companhia de Engenharia de Tráfego de São Paulo (CET-SP) apresenta diariamente um gráfico de lentidão do trânsito na cidade. Com dados obtidos nos 
registros históricos, a CET-SP monitora o índice de lentidão em cerca de 863,6 km de vias da cidade e calcula a média de congestionamento para cada dia da semana e horário, com base nos registros dos mesmos dias da semana e horários de doze meses anteriores, excluindo os meses de Janeiro, Fevereiro, Julho e Dezembro, além de feriados e emendas de feriado (dias atípicos). O gráfico da Figura 7 refere-se a uma sexta-feira, o mesmo dia da semana do evento da greve de ônibus mencionada. Infelizmente, não encontramos os registros do dia da greve, que talvez tenham sido excluídos por se tratar de um dia atípico.

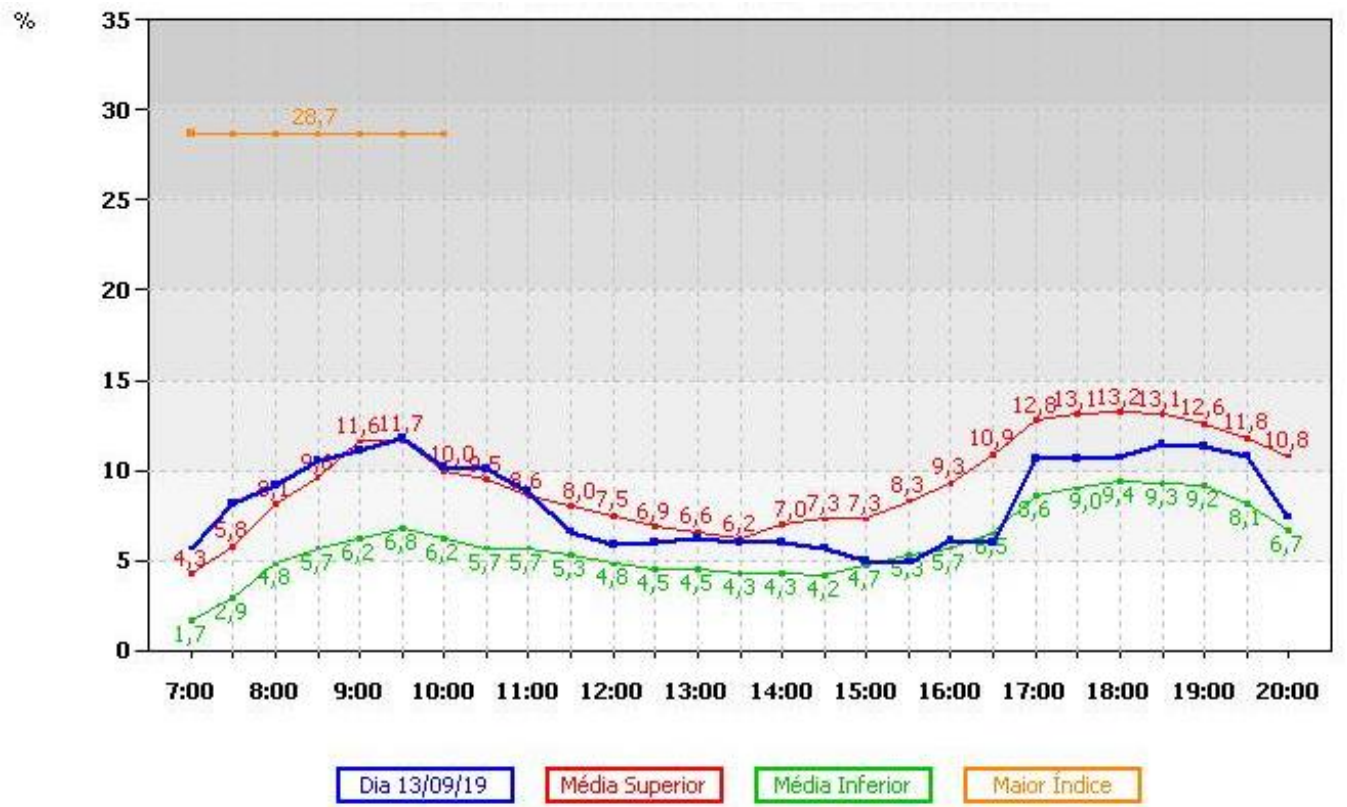

Figura 7 - Percentual de lentidão por hora em São Paulo/SP, em 13/09/2019 (referência 863,6km = 100\%). Fonte: CET-SP (http://cetsp1.cetsp.com.br/monitransmapa/agora/graficolimite.asp)

Como se vê no gráfico, existe uma média superior e uma média inferior, cuja metodologia de cálculo é explicada no website da CET-SP:

O gráfico de lentidão apresenta o índice de lentidão do trânsito registrado a cada 30 minutos, de segunda à sexta, no horário das $7 \mathrm{~h}$ às $20 \mathrm{~h}$, bem como as linhas que indicam o limite inferior e superior, obtidas através de cálculos estatísticos. Esses cálculos são feitos levando-se em conta os dados históricos de lentidão do mesmo dia da semana dos doze meses imediatamente anteriores à data atual. São descartados os valores dos meses de janeiro, fevereiro, julho e dezembro, feriados e emendas de feriados e valores cuja diferença em relação ao valor médio ultrapassa 1,5 desvio padrão. A linha do limite inferior e superior é resultado da aplicação do cálculo de 1 desvio padrão das amostras selecionadas e representa a faixa de valores considerados aceitáveis, quando não há ocorrência que cause grande impacto ao trânsito (CET$\left.\mathrm{SP}^{9}\right)$.

Como explicado pela companhia, qualquer ocorrência com congestionamento acima ou abaixo de 1,5 desvio padrão tomado com base na média aritmética é descartada.

\footnotetext{
${ }^{9}$ cetsp1.cetsp.com.br/monitransmapa/agora/ajuda.htm
} 
Aparentemente, a CET deseja obter uma média comportada e o número de dias descartados acaba sendo grande.

À propósito da fala do prefeito de São Paulo (áudio da rádio $\mathrm{CBN}$ ), ele cita três médias no trecho que transcrevemos abaixo:

[...] o congestionamento às $7 \mathrm{~h}$ da manhã era de $27 \mathrm{~km}$ quando a média é de $37 \mathrm{~km}$, às $7 \mathrm{~h} 30$ era de $37 \mathrm{~km}$ quando a média é $53 \mathrm{~km}$ e agora, às $8 \mathrm{~h}$ da manhã, a gente opera com $58 \mathrm{~km}$ de congestionamento quando a média é de $70 \mathrm{~km}$, ou seja, estamos operando abaixo da média [...] (áudio da rádio CBN São Paulo, trecho entre 1min35s e $1 \min 57 \mathrm{~s})^{10}$

Para deixar a informação mais precisa, observamos que os dados que o prefeito menciona referem-se à média superior (figura 7), senão vejamos:

7h: média superior $=4,3 \%$ de $863,6=37,1 \mathrm{~km}$

7h30min: média superior $=5,8 \%$ de $863,6=50,1 \mathrm{~km}$

$8 \mathrm{~h}$ : média superior $=8,1 \%$ de $863,6=70,0 \mathrm{~km}$

Percebe-se um erro apenas na média das $7 \mathrm{~h} 30$, a qual o prefeito indica ser de $53 \mathrm{~km}$ quando na verdade é de $50,1 \mathrm{~km}$. De qualquer forma, o que o prefeito chama de média de fato não é a média, pois o valor está acrescentado de 1 (um) desvio padrão. De resto, a informação do prefeito poderia até ser questionada quando observamos o gráfico do dia 13/09/2019 (figura 7), exatamente uma semana após a greve dos motoristas de ônibus, no qual o nível de congestionamento entre as $7 \mathrm{~h}$ e $8 \mathrm{~h}$ estava bem acima da média superior. Contudo, nosso objetivo aqui não é fazer esse tipo de questionamento, mas tentar entender o que o senso comum das pessoas trata como sendo a média e como se estabelece critérios para excluir valores discrepantes do seu cálculo.

Quando vemos alunos que não se sentem confortáveis com o resultado da média e, por isso, excluem valores extremos para ela ficar mais bem representada, quando vemos professores também excluindo valores extremos importantes porque eles viesariam o resultado da média ou até o prefeito da cidade forçando uma aproximação para chegar a um resultado dentro da média, percebemos um tipo de comportamento característico que nos chama a atenção.

É claro que poderíamos argumentar que em qualquer um desses casos a substituição da média pela mediana resolveria o problema de representar a tendência central da distribuição de valores, sem haver a necessidade de excluir número algum, e que demonstraria um certo desenvolvimento do raciocínio estatístico. Entretanto, o que nos toca observar com mais atenção é o comportamento, ou seja, a busca por um valor que esteja em

\footnotetext{
${ }^{10} \mathrm{http} / / / c b n . g l o b o r a d i o . g l o b o . c o m / m e d i a / a u d i o / 273670 /$ sistema-nao-e-mais-ou-menos-eficiente-pelaquantid.htm
} 
conformidade com a expectativa da pessoa, um resultado normal, no qual a pessoa se sente confortável.

Ao priorizar um contexto no qual o usuário do conceito estatístico se sente confortável ao invés de buscar uma interpretação plausível para o resultado dos cálculos, nos parece que a realidade fica modificada apenas para agradar quem dela se utiliza. Quando passamos a notar a presença desse viés comportamental, somos capazes de observá-lo em muitas situações tanto dentro da sala de aula quanto fora.

Exemplo 5: Em outra oficina para professores da escola básica e alunos de cursos de licenciatura apresentamos o seguinte problema de probabilidade, idealizado na forma de teste:

No lançamento de duas moedas honestas, sabe-se que um dos resultados foi cara. Qual a probabilidade de os dois resultados terem sido cara?
a) $1 / 4$
b) $1 / 3$
c) $1 / 2$
d) $2 / 3$
e) $3 / 4$

Para resolver esse problema, é útil construir o espaço amostral dos resultados possíveis para o lançamento de duas moedas, que é: $\mathrm{S}=\{\mathrm{CC}, \mathrm{CK}, \mathrm{KC}, \mathrm{KK}\}$, sendo $\mathrm{C}$ para cara e K para coroa. Como sabemos que um dos resultados foi cara, podemos eliminar KK e o espaço amostral fica reduzido a: $\mathrm{S}=\{\mathrm{CC}, \mathrm{CK}, \mathrm{KC}\}$. Agora vemos que o evento "duas caras" representa um de três resultados possíveis, então a resposta correta é a letra (b). No entanto, diversos alunos responderam (c). Observamos que tais alunos não construíram o espaço amostral. Indagados sobre os motivos para não construí-lo, disseram que responderam de forma intuitiva. Nesse caso, a intuição prevaleceu sobre a racionalidade e parece ter deixado os alunos confortáveis para responder um problema que exigiria uma reflexão mais apurada.

Sabemos que a probabilidade é objeto de estudo da Matemática, mas cabe aqui observar que a consideramos como parte da Estatística, tendo em vista que ela traz em si o conceito de aleatoriedade e de incerteza, que são pilares da inferência estatística. Adicionalmente, pontuamos que a probabilidade está presente nos livros de Estatística (Bussab \& Morettin, 2005; McClave, Benson \& Sincich, 2009; Morettin, 2010; Vieira, 2012; Novaes \& Coutinho, 2009; Braule, 2001; Clark \& Downing, 2011).

Entendemos que essa opção pela intuição, pela via rápida de resolução simplificada de um problema, configura também um viés comportamental, talvez de natureza um pouco diferente do que foi descrito nos outros exemplos, mas que pode ser melhor entendido com a ajuda da figura 8, que representa a teoria do sistema dual, a qual afirma que todos nós temos duas formas distintas de pensar, as quais são definidas como sistema 1 e sistema 2. 


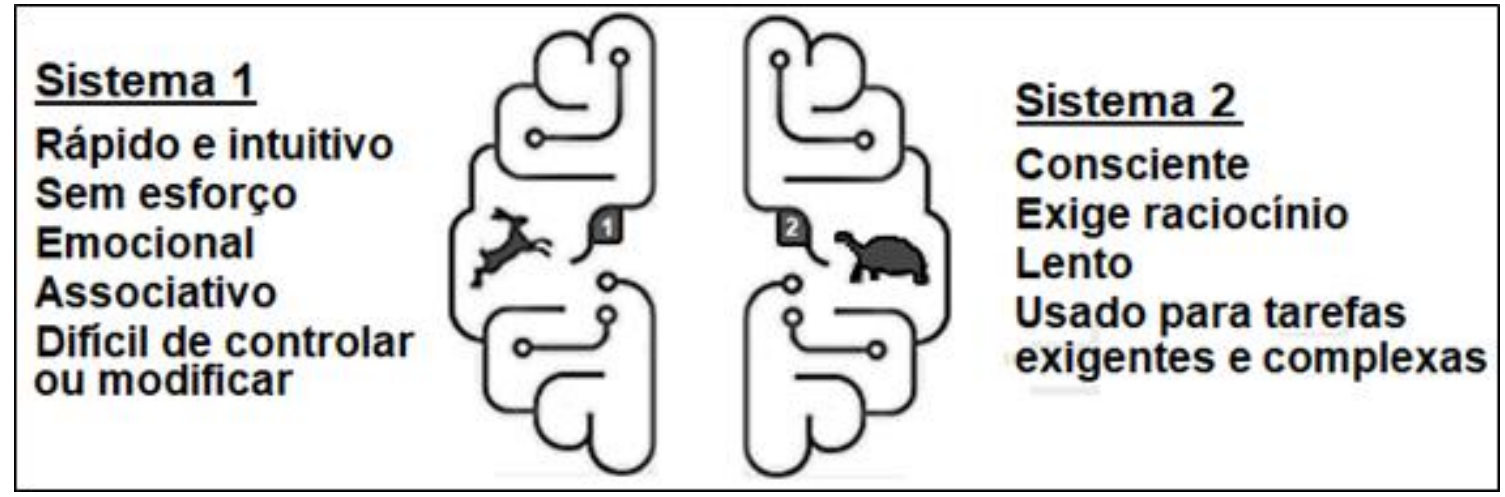

Figura 8 - Esquema da teoria do sistema dual

Fonte: Adaptado de Ávila e Inchausti (2017, p. 23)

O sistema 1 é simples e involuntário, ao passo que o sistema 2 é detalhista, complexo e demanda concentração. Ávila e Inchausti (2017) sugerem que o processo decisório das pessoas segue a lei do menor esforço: o sistema 1, que não pode ser desligado, propõe decisões ao sistema 2, que é mais preguiçoso, por isso ele poupa tempo e responde $o k$ ao sistema 1 , e assim fazemos nossas escolhas.

Nesses cinco exemplos, vimos diferentes situações nas quais o comportamento das pessoas parece ter sido decisivo na escolha da forma com que resolvem os problemas de Estatística. A identificação de alguns padrões de comportamento pode ser bastante útil para promover um ensino/aprendizagem mais eficaz, na medida em que os professores podem ser capazes de prever e contornar tal viés que não se refere necessariamente à falta de conhecimento dos aprendentes, mas a um cuidado em relação à atitude a ser tomada para resolver, interpretar ou validar os resultados.

\section{Considerações finais}

Neste artigo buscamos avançar nos pressupostos teóricos da Educação Estatística no que se refere ao desenvolvimento de algumas competências.

Inicialmente, mostramos que o ensino-aprendizagem de Estatística deve ser estruturado com base no desenvolvimento de três competências: a literacia, o raciocínio e o pensamento estatísticos. Adicionalmente, vimos como alguns estudos buscaram compreender as possíveis inter-relações entre essas competências e as formas de representá-las.

Posteriormente, apresentamos alguns estudos que buscaram identificar os encaminhamentos pedagógicos necessários ao desenvolvimento dessas competências estatísticas. Nessa busca, Campos $(2007,2016)$ encontrou convergências significativas entre esses encaminhamentos e os preceitos da Educação Crítica e da Educação Matemática Crítica, pois esse ambiente estrutura-se com base no diálogo, na problematização, na reflexão e na conscientização, princípios que constituem a Educação Crítica. Além disso, essas ideias trazem subjacentes a si um olhar crítico e reflexivo para o próprio conhecimento. Por essa razão, corroboramos o estudo que entende que a competência crítica deve fazer parte da 
Educação Estatística e deve ser considerada com uma quarta competência dentro dessa área de estudos.

Além disso, mostramos estudos de Perin $(2016,2019)$ sobre relação entre Educação Estatística, Educação Crítica e Educação Matemática Crítica que avançaram no entendimento da competência crítica, que abrange duas vertentes, a sociopolítica e a epistemológica. A vertente sociopolítica refere-se a questionamentos e análises de experiências e situações cotidianas do indivíduo. A epistemológica representa uma crítica ao próprio conhecimento e está ligada ao reconhecimento de algumas fragilidades das ferramentas estatísticas, daí a importância de agregar ideias de diferentes formas e fontes para tirar alguma conclusão e de verificar como e por quem os dados foram produzidos. Mostramos exemplos de aplicação prática dessas duas vertentes da competência crítica.

Por fim, apresentamos uma série de exemplos que, em nosso entendimento, configuram uma nova e importante competência, a qual chamamos de comportamental. Diferentemente das três competências originais, a competência comportamental não está ligada ao aprofundamento dos conteúdos estatísticos nem ao seu aprendizado puro e simples. Ela está ligada às atitudes dos usuários do conhecimento estatístico, que além das três competências primordiais e da competência crítica, exigem uma reflexão sobre a aceitação ou não dos resultados obtidos, a sua validação no contexto adotado, a consciência sobre a possibilidade de provocar um viés no resultado e, ainda, não adotar a intuição como controladora das decisões procedimentais.

Com isso, buscamos cumprir os objetivos deste trabalho, ou seja, contribuir para o aprofundamento do conhecimento sobre a competência crítica e apresentar os indícios de uma nova competência que nos parece ser igualmente importante: a competência comportamental.

Ao pensar sobre essa última competência, nos veio à memória um ditado que diz que a Estatística é a ciência pela qual você "tortura os dados até que eles respondam o que você quer" 11 . Obviamente não podemos concordar com isso, mas possivelmente isso revele um tipo de atitude que esteja relacionado ao viés comportamental das pessoas, que preferem trabalhar para obter os resultados que lhes deixam confortáveis ao invés de encarar a realidade revelada pelos números.

A competência comportamental precisa de mais estudos que permitam aprofundar a sua investigação, de modo a melhor compreendê-la e tipificá-la, evoluindo para permitir a identificação de estratégias para o seu enfrentamento, no sentido de evidenciar vieses comportamentais que levem a falhas de interpretação e mal-uso dos resultados obtidos, entre outros. Se o viés comportamental tem influência na resposta dos estudantes aos problemas de Estatística, então o seu conhecimento deve ser de grande importância para os educadores e pesquisadores da área de Educação Estatística. Por fim, entendemos que pesquisas

\footnotetext{
${ }^{11}$ Adaptação do comentário do economista britânico Ronald Harry Coase, professor emérito da Universidade de Chicago e ganhador do Nobel de Economia em 1991, que disse: "If you torture the data long enough, it will confess to anything", parafraseando Huff, D., How to lie with Statistics, New York: W. W. Norton \& Company, 1954.
} 
DOI: $10.20396 /$ zet.v28i0.8656795

abrangendo as articulações entre as diversas competências também podem contribuir para um melhor entendimento da relevância do tema.

\section{Referências}

Ávila, F.; Inchausti, G. (2017). Economia comportamental aplicada às finanças pessoais. CFP Professional Magazine, São Paulo, ed. 11, p. 20-28. Retirado em 08 de junho de 2019 de: http://www.economiacomportamental.org/wpcontent/uploads/2017/07/CFPMag11_EconomiaComportamental.pdf.

Braule, R. (2001). Estatística aplicada com Excel para cursos de administração e economia. Rio de Janeiro: Campus.

Bussab, W. O. \& Morettin, P. A. (2005). Estatística básica. São Paulo: Saraiva.

Campos, C. R. (2007). Educação estatística: uma investigação acerca dos aspectos relevantes à didática da Estatística em cursos de graduação. Tese (Doutorado em Educação Matemática). Rio Claro: UNESP. Retirado em 02 de julho, 2019, de https://repositorio.unesp.br/handle/11449/102161

Campos, C. R., Wodewotzki, M. L. L., \& Jacobini, O. R. (2011a). Educação estatística: teoria e prática em ambientes de modelagem matemática. Belo Horizonte: Autêntica.

Campos, C. R., Wodewotzki, M. L. L., Jacobini, O. R., \& Ferreira, D. H. L. (2011b). Educação estatística no contexto da educação crítica. Bolema, 24(39), 473 - 494.

Campos, C. R. (2016). Towards critical statistics education: theory and practice. Saarbrücken/Germany: Lambert Academic Publishing.

Campos, C. R., \& Coutinho, C. Q. S. (2019). O problema da amostragem no contexto da educação estatística crítica. Anais da XV Conferência Interamericana de Educação Matemática (pp.1-9). Medellín: Universidad de Medellín. Retirado em 18 de setembro, 2019

de:

file:///C:/Users/Usuario/Downloads/CIAEMColmbiaOproblemadaamostragemdocontext odaedestcrtica.pdf

Cazorla, I. M., Silva Júnior, A. V. \& Santana, E. R. S. (2018). Reflexões sobre o ensino de variáveis conceituais na educação básica. REnCiMa, 9(2), 354-373.

Coutinho, C. Q. S., \& Campos, C. R. (2018). Perspectivas em didática e educação estatística e financeira: reflexões sobre convergências entre letramento matemático, matemacia, letramento estatístico e letramento financeiro. In Oliveira, G.P. (org.), Educação Matemática: epistemologia, didática e tecnologia (pp. 143-180). São Paulo: Livraria da Física..

Delmas, R. C. (2002). Statistical literacy, reasoning and learning: a commentary. Journal of Statistics Education, 10 (3). Retirado em 10 de outubro de 2019 de: www.amstat.org/publications/jse/v10n3/chance.html.

Downing, D. \& Clark, J. (2011). Estatística aplicada. $3^{a}$ ed. São Paulo: Saraiva.

Freire, P. (1965). Educação e liberdade. Rio de Janeiro: Paz e Terra.

Freire, P. (1979). Educação e mudança. Rio de Janeiro: Paz e Terra.

Freire, P. (2014). Educação como prática da liberdade. São Paulo: Paz e Terra.

Zetetiké, Campinas, SP, v.28, 2020, p.1-19-e020003

ISSN 2176-1744 
Hollas, J., \& Bernardi, L. T. M. dos S. (2018). Educação estatística crítica: um olhar sobre os processos educativos. REnCiMa, 9 (2), pp. 72-87.

IBGE (2016). Estimativas da população residente no Brasil e unidades da federação com data de referência em $1^{o}$ de julho de 2016. Brasília: Instituto Brasileiro de Geografia e Estatística. Retirado em 18 de setembro, 2019, de: ftp://ftp.ibge.gov.br/Estimativas_de_Populacao/Estimativas_2016/estimativa_dou_2016 20160913.pdf

McClave, J. T.; Benson, P. G. \& Sincich, T. (2009). Estatística para administração e economia. $10^{\mathrm{a}}$ ed. São Paulo: Pearson Prentice Hall.

Melo, T. B. \& Maçal, M. P. (2012). Educação estatística crítica: um ensaio com alunos do ensino médio e técnico. Anais do III Simpósio Internacional de Pesquisa em Educação Matemática (pp. 1-6). Fortaleza: Faculdade 7 de setembro. Retirado em 18 de setembro, 2019, de: http://proativa.virtual.ufc.br/sipemat2012/papers/192/submission/director/192.pdf

Ministério da Educação (MEC). (2017). Resolução cne/cp nº 2, de 22 de dezembro de 2017. Institui Base Nacional Comum Curricular. Diário Oficial República Federativa do Brasil. Brasília.

Morettin, L. G. (2010). Estatística básica: probabilidade e inferência. São Paulo: Pearson.

Morettin, P. A. \& Bussab, W. O. (2005). Estatística Básica. São Paulo: Saraiva.

Novaes, D. V. \& Coutinho, C. Q. S. (2009). Estatística para educação profissional. São Paulo: Atlas.

Perin, A. P. (2016). Educação estatística crítica: um estudo das práticas discentes em um curso de tecnologia. Anais do XX Encontro Brasileiro de Estudantes de Pós-Graduação em Educação Matemática (1-11). Curitiba: Associação Nacional de Pós Graduação e Pesquisa em Educação Matemática. Retirado em 18 de setembro, 2019, de: http://www.ebrapem2016.ufpr.br/wpcontent/uploads/2016/04/gd12_andrea_pavan_perin.pdf

Perin, A. P. (2019). Educação Estatística Crítica: um estudo das práticas discentes em um curso de tecnologia. Tese (Doutorado em Educação Matemática). Rio Claro: UNESP. Retirado em 02 de julho, 2019, de: https://repositorio.unesp.br/handle/11449/182412

Samá, S. (2018). Caminhos trilhados pelo GT12 nas pesquisas em Educação Estatística no Brasil. Anais do VII Seminário Internacional de Pesquisa em Educação Matemática. (pp.1-12). Foz do Iguaçu: Sociedade Brasileira de Educação Matemática. Retirado em 10 de junho, 2019, de: http://www.sbemparana.com.br/eventos/index.php/SIPEM/VII_SIPEM/paper/view/547/2 $\underline{49}$

Sampaio, L. O. (2010). Educação estatística crítica: uma possibilidade? Dissertação (Mestrado em Educação Matemática). Rio Claro: UNESP. Retirado em 06 de julho, 2019, de: https://repositorio.unesp.br/handle/11449/91123

Skovsmose, O. (2014a). Educação Matemática Crítica: a questão da democracia. $3^{\mathrm{a}}$ ed. Campinas: Papirus.

Skovsmose, O. (2014b). Um convite à Educação Matemática Crítica. Campinas: Papirus. 
DOI: $10.20396 /$ zet.v28i0.8656795

Skovsmose, O. (2018). Desafios da reflexão em Educação Matemática Crítica. Campinas: Papirus.

Vieira, S. (2012). Estatística para a qualidade. $2^{\mathrm{a}}$ ed. Rio de Janeiro: Elsevier.

Zieffler, A.; Garfield, J. \& Fry, E. (2018). What is Statistics Education? In Ben-Zvi, D.; Makar, K.; Garfield, J. (Org.). International Handbook of Research in Statistics Education (pp. 37-71). Gewerbestrasse: Springer International Handbooks of Education. 